\title{
Prolonged Irritative Voiding Symptoms Due to Enterobius vermicularis Bladder Infestation in an Adult Patient
}

\author{
Zein Mohamed Sammour, Cristiano Mendes Gomes, Andre Luiz Farinhas Tome, Homero Bruschini and Miguel Srougi
} Division of Urology, University of São Paulo, School of Medicine; São Paulo, SP, Brazil

\begin{abstract}
Enterobius vermicularis (pinworm) is one of the most prevalent intestinal parasites in the world. The urinary tract is rarely affected and few cases have been reported. We report a case of bladder infestation by mature female worms of $E$. vermicularis in a woman presenting with irritative voiding symptoms.

Key-Words: Enterobiasis, urinary tract infection, bladder.
\end{abstract}

Enterobius vermicularis is one of the most prevalent intestinal parasites in the world. The urinary tract is rarely affected and few cases have been reported. We report a case of bladder infestation by mature female worms of $E$. vermicularis in a woman.

\section{Case Report}

A 54 year-old woman presented with a history of irritative voiding symptoms for one month. She had recently been treated with norfloxacin, with no improvement. Urinalysis revealed leucocyturia, and a urine culture was negative. An abdominal CT scan showed an $8 \mathrm{~mm}$ stone in the distal left ureter, which was removed endoscopically. Cystoscopy was normal upon ureteroscopic stone removal. The voiding symptoms did not improve after ureterolithotripsy, and she had persistent leucocyturia despite negative urine cultures and three courses of antibiotics. A second CT did not reveal urological abnormalities. She was treated with analgesics; after two months the patient noticed two worms in her own urine and brought them to the clinic. The worms were examined in a parasitology lab and a diagnosis of mature female Oxyurus worms (Enterobius vermicularis) was made. The patient was treated with $200 \mathrm{mg}$ mebendazole once a day, for three days, with complete resolution of the voiding symptoms and normalization of urinalysis. A scotch-tape test applied to the perianal and perineal areas after treatment was negative. In the follow-up after six months, the patient remained asymptomatic.

\section{Discussion}

Enterobiasis (oxyuriasis or pinworm infection) is the most common helminth infection in the USA and Western Europe, particularly amongst school-aged children.[1] Humans are the only host for the E. vermicularis, which is acquired by the ingestion of infective eggs by direct anus-to-mouth transfer. Adult worms of $E$. vermicularis are usually found in the

Received on 28 April 2008; revised 20 June 2008.

Address for correspondence: Dr. Cristiano Mendes Gomes. Hospital das Clinicas da Faculdade de Medicina da USP, Divisao de Clinica Urologica Avenida Dr. Eneas de Carvalho Aguiar, 255 - Sala 710F - 7 Andar - Zip code: 05403-000 - Sao Paulo - SP - Brazil. Phone: (0 55 11) 30698080. Fax: (0 55 11) 3064-7013. E-mail: crismgomes@uol.com.br.

The Brazilian Journal of Infectious Diseases

2008;12(4):352. (C) 2008 by The Brazilian Journal of Infectious Diseases and Contexto Publishing. All rights reserved. caecum and the adjacent regions of the large and small intestines. Downward migration to the peri-anal and perineal region is the common path for gravid females in their attempt to expel eggs [1]. Occasional invasion of unusual sites has been reported, most commonly the female genital tract [2,3].

The finding of eggs in the urine of children has been described in the literature; it generally occurs by autoinnoculation [4-6]. To our knowledge, only two cases of infestation of the urinary tract by adult $E$. vermicularis have been reported $[7,8]$. Diagnosis of intestinal pinworm infection is commonly made by a scotch-tape test applied to the perineal and perianal areas of the patient during the night, based on the finding of eggs of this parasite. Fecal exams are generally negative [1].

Mebendazole (100 mg orally in a single dose, repeated in one week) is the standard treatment for most pinworm infections. However, less than $2 \%$ of the drug is absorbed and an additional agent may be needed for the treatment of urinary infections. Ivermectin $(200 \mu \mathrm{g} / \mathrm{kg}$ body weight, single dose) may be a good choice, given its pharmacological distribution in the urinary tract [1].

In conclusion, pinworm infection can be a differential diagnosis in patients with low urinary tract symptoms and negative urine cultures, though it requires a high index of suspicion.

\section{References}

1. Burkhart C.N., Burkhart C.G. Assessment of frequency, transmission, and genitourinary complications of enterobiasis (pinworms). Int J Dermatol 2005;44:837-40.

2. Avram E., Yakovlevitz M., Schachter A. Cytologic detection of Enterobius vermicularis and Strongyloides stercoralis in routine cervicovaginal smears and urocytograms. Acta cytol 1984;28:468-70.

3. Mayers C.P., Purvis R.J. Manifestations of pinworms. Can Med Assoc J 1970;103:489-93.

4. Ok Ü.Z., Ertan P., Limoncu E., et al. Relationship between pinworm and urinary tract infections in young girls. APMIS 1999;107:474-6.

5. Sachdev Y.V., Howards S.S. Enterobius vermicularis infestation and secondary enuresis. J Urol 1975;113:143-4.

6. Adungo N.I., Ondijo S.O., Pamba H.O. Observation of Enterobius vermicularis ova in urine: 3 case reports. East Afr Med J 1986;63:676-8.

7. Al-Allaf G.A., Hayatee Z.G. Recto-urethral migration of Enterobius vermicularis. Trans R Soc Trop Med Hyg 1977;71:351.

8. Symmers W.S.C. Pathology of oxyuriasis, with special reference to granulomas due to presence of Oxyuris vermicularis (Enterobius vermicularis) and its ova in the tissues. Arch Path 1950;50:475. 